\title{
La doble aportación laboral de las mujeres (1940-1965): Estrategias familiares en los hogares obreros del sur de Madrid para mejorar la economía doméstica ${ }^{1}$
}

JULIO A. FERNÁNDEZ GÓMEZ

Fundación por el Empleo. Fuenlabrada

\begin{abstract}
La idea de que las familias corrientes pueden mantenerse adecuadamente con los ingresos de un trabajador es una peligrosa falacia. Algunas familias de la aristocracia trabajadora y de las clases medias pueden, evidentemente, mantenerse de forma adecuada de esta manera. Pero deducir de ahí que la mayor parte de las familias de la gente trabajadora corriente no necesitan, y nunca han necesitado, del salario de otras personas es algo totalmente injustificado (Pahl 1991: 114).
\end{abstract}

La afirmación de Ray E. Pahl, tomada de su Divisiones del trabajo, nos introduce en un aspecto de particular importancia por lo que respecta a las condiciones materiales de existencia de las familias obreras: dado que éstas apenas poseen bienes que generen rentas adicionales a su propia capacidad de trabajo (dinero, tierras, inmuebles, etc.), sus niveles de bienestar son, en general, proporcionales a los recursos humanos de que disponen; concretamente al cociente "productores/consumidores" que conviven en un momento dado dentro del núcleo familiar. $\mathrm{O}$, por decirlo con otras palabras, en los hogares obreros "las condiciones de vida, el ingreso, la organización del presupuesto, están íntimamente ligados a las estructuras familiares" (Chombart de Lauwe 1978: 334) ${ }^{2}$. Estructuras que

1 Este artículo tiene su origen en una investigación más amplia, que trata de las condiciones de trabajo y vida afrontadas por las familias de origen rural que llegaron a la periferia sur de Madrid durante los años en que se produjo la consolidación industrial de la capital (1940-1965). Investigación realizada para la obtención del Grado de Doctor en Sociología (Fernández Gómez 2000), de la que aquí se retoman diversos materiales, especialmente algunos "cortes" de las 32 entrevistas en profundidad, semidirigidas y grabadas, que se llevaron a cabo con tal ocasión -utilizando el método de las "historias de vidan- y que aquí se citarán con el mismo número que lo fueron en la investigación que los enmarca. El autor aprovecha la nota para agradecer al profesor Juan José Castillo Alonso, director de la citada tesis doctoral, tanto la dedicación y argumentos dispensados a lo largo de su realización como su estimulante y continuo magisterio en el oficio de sociólogo.

2 Como algunos estudios histórico-demográficos han puesto de manifiesto, las economías familiares han guardado siempre una estrecha relación con el tipo de estruc- 
el propio ciclo vital va modificando con el tiempo, de modo que las unidades familiares atraviesan por diferentes etapas de mayor o menor bienestar a lo largo de su existencia, coincidiendo el período más desfavorable con la llegada y crianza de los hijos; situación que comienza a cambiar cuando éstos van pasando a la edad activa y, así, contribuyen económicamente al presupuesto familiar.

Por otro lado, junto a las estructuras que presenten las unidades familiares, el poder adquisitivo que puedan alcanzar éstas dependerá, a su vez, de la cuantía de los salarios que perciben sus miembros. $Y$, en este sentido, se ha de reseñar que durante el período que abarca nuestra investigación (1940-1965) las rentas salariales reales fueron muy bajas, hasta el punto de que el nivel de consumo obrero anterior a la guerra civil no pudo alcanzarse hasta mediados de los años cincuenta (Ferner y Fina 1988: 153). Es más, durante esa década —en la que se produjo un notable crecimiento económico- el imparable proceso inflacionista que vivió la economía española menoscabó siempre la participación del trabajo en la Renta Nacional, manteniendo el poder adquisitivo de los salarios en niveles relativos muy bajos ${ }^{3}$. De esta forma, sólo a comienzos de los años sesenta -cuando la Ley de Convenios Colectivos de 1958 empezó a surtir efectos- los salarios base de nuestros trabajadores mejoraron sensiblemente, si bien tales incrementos resultaban todavía insuficientes para garantizar el mínimo vital de una familia madrileña de cuatro personas (Babiano 1995: 157 y ss.).

Así las cosas, en aquellos hogares donde convivían mayor número de consumidores que de productores y, además, las rentas salariales obtenidas por estos últimos eran muy bajas, las familias pusieron en marcha estrategias destinadas a proporcionar ocupación al mayor número de miembros posible. Circunstancia que aceleró la transición laboral de las muje-

tura grupal que presentaban los hogares. Los trabajos de Chayanov (1985) sobre la forma de organizarse de las familas campesinas, los de Harris (1986) respecto a las familias obrero-industriales, las Aproximaciones a la historia de la familia occidental de Anderson (1988), o algunos textos de la compilación de Burguière et al. (1988), son buena muestra de lo que aquí se plantea.

3 De hecho, durante los años cincuenta comenzaron a producirse las primeras movilizaciones obreras durante el franquismo. Protestas que el Régimen resolvía sistemáticamente utilizando la acción represora para, inmediatamente después, incrementar los salarios nominales que decretaban las Reglamentaciones del Trabajo. Pero esos incrementos sólo paliaban la pérdida de poder adquisitivo momentáneamente pues la inflación volvía a colocar, en muy breve tiempo, los salarios obreros en la situación de partida. Un modus operandi que llegó a la paroxía en 1956, año en que se produjeron dos importantes subidas en los salarios nominales (Cfr. Velarde 1969: 473-477). 
res, como lo muestra que sólo en la década de los cuarenta, y según los datos de los Censos de Población con que contamos para ese período, las mujeres activas pasasen de 850.000 a 1.317 .000 , incremento de un $55 \%$ de su peso específico en la actividad que contrasta con el que arrojó durante ese decenio el de los hombres: 17\% (Cfr. Fernández de Castro 1973: 49-50). Es más, si consideramos en su conjunto el período comprendido entre 1940 y 1960, y dado que la tasa de actividad de los hombres estuvo prácticamente saturada durante aquellos años, encontraremos que casi el $50 \%$ del crecimiento absoluto de la población activa en ese tiempo fue debido a la incorporación de la mujer al mundo del trabajo asalariado (Espina 1982: 308).

Con todo, la participación de la mujer en el trabajo fue mayor de la que registraron las fuentes estadístico-demográficas de que disponemos Censos y Padrones-, pues en ellas no se recogió el trabajo sumergido de la mitad femenina; actividad que, además, muchas de ellas tuvieron que compaginar con sus tareas del hogar.

En este artículo pretendemos mostrar algunos aspectos de esa doble aportación laboral, complementando los datos sociodemográficos aficiales" con la información cualitativa, obtenida a través de entrevistas realizadas a un grupo de personas que llegaron a Villaverde -antiguo municipio colindante con el sur de Madrid y posterior distrito de la capitaldurante el período 1940-1965. Población obrero-emigrante que llegó allí buscando mejores condiciones de vida que las mantenidas en sus lugares de origen, y que aquí se toma como ejemplo de la asentada en la periferia sur madrileña a lo largo de esos años.

\section{El tRABAJO ASALARIADO EN LA ECONOMÍA FORMAL DURANTE LOS AÑOS CUARENTA}

Durante los veinticinco años que siguieron al final de la guerra civil la constante llegada de emigrantes a Villaverde hizo que, a lo largo de ese período, el conjunto de su población presentase siempre rasgos acusados de juventud. Un hecho del que, por ejemplo, daba buena muestra su Padrón de Habitantes correspondiente a 1945, donde se podía apreciar que el $33 \%$ de los 15.207 residentes en la localidad tenía menos de 15 años, y el $77 \%$ no llegaba a los 40 , razón por la que sólo 4.597 personas declaraban tener alguna ocupación: el 30,2\% de todos los habitantes y el $47,5 \%$ de los que tenían edad para trabajar.

Con la finalidad de conocer quiénes eran los miembros del hogar que en mayor medida aportaban a sus respectivas economías familiares el 
salario derivado de su trabajo en la "economía formal", hemos elaborado la Tabla 1, donde puede verse cómo se distribuían las personas ocupadas, en función del parentesco que mantenían dentro de sus hogares, el peso relativo que tenían dentro de la población potencialmente activa (1465 años) y, finalmente, la proporción de activos que estaban oficialmente ocupados.

En dicha tabla puede observarse que, dentro del conjunto de ocupados en 1945, los trabajadores asalariados se concentraban sobre todo en los "Cabeza de Familia" (64,5\%), un grupo de parentesco cuyos individuos eran fundamentalmente hombres - sólo 147 eran mujeres- y donde casi todos los que tenían edad para trabajar lo hacían $(93,5 \%)^{4}$. Entre ellos, el mayor peso específico correspondía a los ocupados como jornaleros o peones de la industria o la construcción (61\%), un 16\% tenía alguna profesión que expresaba cierta cualificación, y 5 de cada 100 no eran obreros sino empleados. Además, y según los datos contenidos en el citado Padrón, el sueldo diario promedio que recibían estas personas era de 12 pesetas; agrupándose el $91 \%$ en los siguientes intervalos de jornales: un $62 \%$ ganaba entre 9,85 y 12 pesetas, un $21,2 \%$ entre 12,25 y 15 , y el $7,8 \%$ restante recibía un salario comprendido entre 15,5 y 18 pesetas.

Pero si una gran parte de los ingresos derivados del trabajo asalariado que entraba en los hogares provenía de los miembros que encabezaban la familia, algunos otros recibían también el complemento que aportaba el trabajo de los "Hijos". Así parece confirmarlo el hecho de que el $26 \%$ de la población ocupada perteneciese a este grupo de parentesco, si bien no podemos concretar la proporción de hogares en que esto ocurría, ni si en ellos eran uno o varios los jóvenes ocupados por familia. Cuestión nada baladí por otro lado, pues tal aportación podía llegar a ser muy importante en algunos casos:

Empecé ganando 4,50 pesetas diarias [en 1943], que era aprendiz de $4 .^{\circ}$ me parece. 4,50 y una peseta que nos daban como prima. [...] Mi padre entonces andaría en las 10 u 11 pesetas, y mi hermano y yo también ganábamos eso entre los dos. ¡Hombre!, cuando empezamos a trabajar mi hermano y yo pues me acuerdo que en mi casa éramos capitanes generales con respecto a otros vecinos (Entrevista $n .^{\circ} 7$ ).

Entre los hijos que trabajaban predominaban también los jornaleros y peones (48\%); y, aunque existía en este colectivo algo más de cualifica-

4 En realidad, salvo en los casos de viudas con hijos trabajando, de jubilados por enfermedad o algún otro caso similar que explica la diferencia entre los "Cabeza de Familia" ocupados y los potencialmente activos en 205 individuos, todos los miembros familiares con esta categoría de parentesco trabajaban. 
ción que en el formado por sus padres (18,5\%), casi 1 de cada 4 hijos ocupados fueron registrados como aprendices o similares. El sueldo medio diario que percibían era de 8,6 pesetas, promedio que se aproximaba bastante a la del grupo anterior, dado que el $48 \%$ de los hijos que trabajaban tenía 20 o más años, una edad en la que la cuantía de su salario comenzaba a asemejarse a la de sus mayores. Especialmente cuando el asalariado era varón pues, como muestra la distribución porcentual de frecuencias observadas en los jornales percibidos por hijos e hijas (Véase Tabla 2), existía una fuerte diferencia salarial en función del sexo.

Diferencia entre el jornal aportado por unos y por otras que no estaba mediatizada por su edad, ya que en el intervalo 14-19 años -al que correspondían los salarios más bajos- hemos encontrado una mayor proporción de chicos $(51,2 \%)$ que de chicas $(45,6 \%)$ en sus respectivos grupos, sino que tenía su origen tanto en el tipo de actividad que realizaban como en la pertenencia a una u otra categoría de "género". De la primera afirmación da cuenta que el $42 \%$ de las hijas trabajaban en el "Servicio Doméstico", donde su jornal medio era de 4,9 pesetas, mientras que el $66,5 \%$ de los hijos lo hacían como "Artesanos y Jornaleros" ganando 10,1 pesetas de media. De la segunda, el hecho de que dentro de esta última categoría laboral —en la que trabajaban el $38 \%$ de las chicas formalmente ocupadas- el jornal que les pagaban venía siendo un 30\% más bajo (7,1 pesetas) que el recibido por los chicos ${ }^{5}$.

En estas circunstancias, es muy posible que tales diferencias contribuyesen por entonces a que muchas de nuestras familias obreras buscasen de forma inmediata la colocación de los hijos y no prestasen tanta importancia a la de las hijas, prefiriendo que éstas se quedasen en casa, ayudando a sus madres en las labores domésticas ${ }^{6}$. Precisamente el lugar

5 Diferencial de porcentaje idéntico, por otro lado, al que la propia legislación laboral estipulaba para el caso de los salarios de hombres y mujeres, aún realizando tareas idénticas o similares. Véase al respecto, por ejemplo, el tenor literal con que se cerraba el artículo 32 de la Reglamentación del Trabajo de la Industria Siderometalúngica de 1942: "El personal femenino obrero percibirá un salario equivalente al 70 por 100 del fijado para el masculino [...] para trabajos iguales o análogos".

6 En esa línea apunta el siguiente relato de uno de nuestros informantes: «Dejé de ir al colegio a los 14 años [1944], porque jclaro! la posguerra fue muy mala y entonces en cuanto podía ponerse un hijo a trabajar pues lo metían donde fuese. A mí mi madre no es que me metiese prisa ¿no?, pero yo veía como estábamos y entré a trabajar en un taller de hojalatería. [...] No, entonces mis hermanas no trabajaban ninguna de las dos, porque la mayor ayudaba a mi madre en la casa y la pequeña es que nunca ha trabajao fuera de la casa. [...] Mi otro hermano también, como yo, en cuanto tuvo edad se puso a trabajar" (Entrevista $n .^{\circ} 10$ ). 
que parecía destinársele a las "Esposas" casi en su totalidad, pues —como puede apreciarse en la Tabla 1- este grupo de parentesco sólo representaba al $0,5 \%$ de las personas ocupadas en el trabajo asalariado "formaln, mientras que suponía el $27,7 \%$ de los potencialmente activos en el conjunto de la población. De esta forma sería posible explicar, prima facie, buena parte de las motivaciones que, finalmente, hacían posible que sólo 9 de cada 100 chicas en edad laboral trabajasen, mientras que lo hacían 68 de cada 100 chicos.

Sin embargo, atribuir esa baja proporción de trabajo femenino a la discriminación salarial por género o al patriarcalismo cultural, especialmente durante unos años en que los ingresos corrientes de la mayor parte de las familias no eran suficientes para atajar las pésimas condiciones de vida que padecían, se nos antoja una respuesta incompleta ${ }^{7}$.

Sin duda, en aquellos hogares donde además de la persona que encabezaba la familia hubiese algún hijo ocupado y su extensión fuese moderada - 4 ó 5 personas - no haría tanta falta el ingreso derivado del trabajo de otros miembros, por lo que tanto la discriminación salarial como el patriarcalismo cultural podrían estar jugando allí cierto papel coercitivo respecto a la entrada de las hijas en el trabajo, especialmente en el doméstico por estar peor pagado. Sin embargo, éste no debía ser el caso de la mayoría de los hogares villaverdenses pues, aun cuando hipotéticamente supusiéramos que los hijos/hijas que trabajaban por entonces (1.197) se repartían unitariamente por cada grupo familiar (3.311, si consideramos su número igual al de cabezas de familia), quedarían más de 2.000 familias con un sólo jornal como ingreso, y no todas ellas estarían compuestas de niños en edad no laboral. Es decir, parece bastante probable que, como por otro lado suele ocurrir con frecuencia, los datos del Padrón de Habitantes de 1945 no ofrezcan cumplido detalle de las personas que realmente trabajaban, fuese a jornada completa o parcial; especialmente de las mujeres que, como diríamos hoy, se encontraban en el trabajo sumergido.

\footnotetext{
7 Téngase en cuenta que durante los años cuarenta los niveles salariales reales fueron similares a los existentes antes de la I Guerra Mundial (Carreras 1989: 17); y que toda la década estuvo presidida por una disparatada política de precios tasados que propició el desvío de la mayor parte de los productos alimenticios al mercado negro, donde alcanzaban precios exorbitantes respecto a los oficialmente estipulados (Barciela López 1998: 86 y ss.). Es más, por lo que sabemos para el caso de los residentes en Madrid, "el desfase entre los salarios nominales y la evolución de los precios se intensificó entre 1941 y 1951", lo que llevó aparejado que "el coste de la subsistencia básica diaria de una familia trabajadora con dos hijos se elevase en un 100 por 100 en el período 1947-1951, mientras los salarios no seguían el mismo ritmo" (Bahamonde 1993: 19).
} 
De ello trataremos más adelante, por lo que seguiremos ahora con los "oficialmente" ocupados, grupo de trabajadores que cerraban los 309 "Familiares Allegados" y los 118 que hemos denominado como "Otros". Entre los primeros solían figurar hermanos, sobrinos, primos o incluso hijos políticos de alguno de los cónyuges. En el caso de los segundos sus apellidos no parecen indicar relación familiar alguna respecto a aquéllos. Dos grupos de parentesco que, para lo que aquí interesa, pueden ser considerados como uno solo: el de las personas hospedadas en los hogares de referencia. En conjunto componían un $9 \%$ de la población ocupada y, según nos informan nuestros entrevistados, aunque algunos contribuían al gasto familiar aportando todo su salario, la mayoría destinaban a tal contribución sólo una parte del mismo, como contraprestación al gasto y trabajo que generaban dentro del hogar:

Me compenetré enseguida con mis tíos. Para mí eran como mis padres. Yo allí era uno más, el dinero que ganaba se lo entregaba a mi tía y ella me decía: "tanto para comer y dormir y tanto para la cartillaw. Porque lo primero que hicieron fue abrirme una cartilla (Entrevista n. ${ }^{\circ} 8$ ).

En suma, según los datos estadístico-demográficos de que disponemos para 1945, la contribución salarial al bienestar del hogar obrero villaverdense provenía fundamentalmente, y en términos generales, de los ingresos aportados por el cabeza de familia y aquellos hijos varones que tenían edad para trabajar, pues ni el trabajo de las mujeres ni los ingresos derivados a los hogares por las personas ocupadas hospedadas en ellos parecían tener por entonces un gran peso específico dentro de las economías familiares "tipo".

No obstante, en el transcurso de los quince años siguientes - período en el que se produjo la consolidación industrial de la zona y, debido a ello, un gran aumento de los puestos de trabajo- la situación comenzó a experimentar un cierto cambio, tomando mayor pujanza las aportaciones de los huéspedes y, sobre todo, de las hijas en edad de trabajar.

2. LA TRANSICIÓN LABORAL DE LAS MUJERES DEL SUR DE MADRID A LA LUZ DE LOS DATOS SOCIO-DEMOGRÁFICOS (1945-1960): ALGUNAS MOTIVACIONES PARA ESE CAMBIO

En 1960, la población residente en Villaverde ascendía a 144.884 habitantes. De ellos, un 30,5\% tenía menos de 15 años de edad, el 65,4\% entre 15 y 64, y sólo un 4,1\% más de 64 (Cfr. Ministerio de la Vivienda 1961). Es decir, en los tres lustros habidos entre 1945 y 1960 la formación social villaverdense no sólo se multiplicó casi por 10, sino que, tam- 
bién, incrementó en 2 puntos porcentuales su población activa. Con todo, el cambio más significativo se produjo en el montante de población ocupada, que ascendió en 8 puntos (30,2\% en 1945 y 38,2\% en 1960); buena parte de ellos aportados por las mujeres, que duplicaron con creces su presencia relativa en la ocupación, alcanzando la tasa de trabajo femenino el 15,6\% en 1960 cuando quince años antes era sólo del 6,7\%.

Esta mayor inserción de las mujeres del sur de Madrid en el mundo del trabajo formalmente asalariado corrió pareja a la vivida por sus homónimas en el conjunto del país, como consecuencia - tal y como quedó apuntado en la introducción - de unas políticas de gestión de la fuerza de trabajo que, basadas en el pago de salarios extremadamente bajos, propiciaban estrategias familiares que perseguían incrementar los ingresos aportados por los varones a la economía familiar. De hecho, todavía en 1950 los obreros madrileños distaban mucho de mantener un nivel de vida siquiera cercano a las $2 / 3$ partes del que habían tenido en $1936^{8}$.

No es de extrañar, por tanto, que aquel parco poder adquisitivo se constituyese, para una buena parte de las hijas que integraban las familias obreras de la periferia madrileña, en la principal motivación que presidió su entrada en la ocupación formal a lo largo de la década de los cincuenta. Dos de aquellas jóvenes trabajadoras se referían a esta cuestión de la siguiente forma:

\begin{abstract}
Yo quería entrar a trabajar porque es que casi no teníamos para vivir. Mi madre ganaba poco, mi hermano estaba estudiando ya "Comercio", yo acababa de cumplir los 14 años [1954], y entonces es cuando me metieron en Giralt [Laporta] (Entrevista n. ${ }^{\circ}$ 26).

Cuando vinimos a San Cristóbal [1959] yo tenía 14 años y entonces me puse a trabajar, porque entonces te ponías a trabajar muy joven. Yo no me acuerdo de lo que ganarían ni mi padre ni mi madre, pero de lo que sí me acuerdo es de que en mi casa no sobraba el dinero (Entrevista n. ${ }^{\circ} 28$ ).
\end{abstract}

En ambos casos se trataba de familias con sólo tres personas conviviendo en el hogar. Pero mientras el primer testimonio trasluce la necesidad de complementar imperiosamente el bajo salario obtenido por un solo miembro de la familia, una mujer viuda con dos hijos y en espera de que los estudios del varón permitieran a medio plazo una situación

8 La propia Cámara Oficial de Comercio y de la Industria de Madrid (1951: 277278), tomando como índice 100 el nivel de vida obrero en el Madrid de 1936, calculaba los siguientes índices, según categorías y empleos a la altura de 1950: Mecanógrafos o Escribientes (65,5); Ordenanzas (51,4); Oficial Ebanista (54,5); Oficial Ajustador $(61,2)$; Oficial Albañil $(65,3)$; Peón de la Construcción $(51,6)$. 
económico-familiar más saneada; en el segundo, perteneciente a una hija única, cuyo padre trabajaba como conductor de camiones en una empresa metalúrgica villaverdense y la madre como asistenta doméstica por horas, parece apreciarse ya un cierto cambio en las estrategias familiares respecto a una mayor entrada de las hijas en la ocupación.

Efectivamente, y como ya vimos a través de las cifras que arrojaban los censos y padrones correspondientes, en sólo quince años se había duplicado con creces la participación femenina en el empleo; pero que todavía a la altura de 1960 las mujeres villaverdenses apenas alcanzasen a ser el $16 \%$ de todos los ocupados de aquel antiguo término municipal suponía una escasa aportación femenina en el ámbito del trabajo, como lo muestra que en el conjunto de Madrid dicho porcentaje alcanzase en ese mismo año casi 10 puntos más (25,2\%). Diferencia que un Informe FOESSA atribuía tanto a una mayor conservación del puesto de trabajo por parte de las madrileñas casadas como, sobre todo, a que las mujeres residentes en la periferia contraían matrimonio a edades más tempranas, "con lo cual dejalbaln en la mayoría de los casos el trabajo para dedicarse al hogar" (FOESSA 1967: 60). De tal forma que las entradas en la actividad laboral de las jóvenes residentes en Villaverde no hacían sino suplir en buena medida las salidas de sus antecesoras cuando se casaban, con lo que el total acumulado de población femenina ocupada permanecía por debajo del presentado por el conjunto de las mujeres madrileñas.

Ahora bien, en lo que no entraba el citado Informe era en las razones subyacentes al mayor abandono del trabajo que las mujeres de la periferia madrileña registraban cuando se casaban. Una cuestión para la que sí buscó respuestas el autor de un pionero trabajo sociológico realizado a mediados de los sesenta en el barrio villaverdense de Orcasitas, argumentando razones culturales y socio-económicas (Cfr. Alonso Hinojal 1969: 25-49).

En cuanto a las primeras, constataba una clara actitud contraria por parte del $80 \%$ de los maridos respecto al trabajo de la mujer casada fuera del hogar, llegando a una cuarta parte de ellos los que veían con desagrado que trabajasen las solteras. Es más, aun cuando el $71 \%$ de las esposas había trabajado antes de contraer matrimonio, sólo la tercera parte deseaba volver a trabajar como asalariadas. Así, no es de extrañar que una de nuestras entrevistadas nos dijera, tajantemente:

Ahora la mujeres siguen trabajando, pero es que antes estábamos locas por casarnos y dejar de trabajar (Entrevista n. $^{\circ} 28$ ).

Y cuando esas pautas culturales no incidían en la salida de la mujer del trabajo al casarse, lo hacían las normativas legales. Así, una trabaja- 
dora de Renfe desde mediados de los cuarenta debió abandonar su puesto de trabajo al casarse (1955) por mor de una ley que se creó al efecto. Ella nos lo relataba de la siguiente forma:

Cuando yo entré a trabajar en las oficinas de Renfe entré con la condición de que cuando me casara cesaba, "licencia por matrimonio le llamaban a eso. [...] lo dijo Franco, que era el que mandaba, y sanseacabó. Hicieron una Ley. Las de Telefónica, las de Renfe y las de ... no sé que otro sitio, pero había otra empresa del Estado que también te tenías que ir cuando te casaras ... Porque ¡claro!, al casarnos pues ¿qué pasaba? que enseguida nos embarazaban y entonces, nada, los puestos [de trabajol para los que tenían pantalones, que entonces no se llevaba que las mujeres llevásemos pantalones. [...] Algunas compañeras que quedaron viudas reingresaron. Y después, en el año 62, derogaron esa ley. O sea, desde el 46 , que fue cuando yo entré, que me pilló en la primera promoción de oposiciones, pues desde el 46 hasta el 62 estuvo esa Ley (Entrevista n. ${ }^{\circ} 1$ ).

En cuanto al segundo tipo de razones apuntadas por Alonso Hinojal (las socio-económicas), y sin duda retro-alimentadas por ese modelo de comportamiento dominante en el que el lugar del marido era el trabajo y el de la mujer la casa, aparecía claramente un criterio de uracionalidad económica" que justificaba la marcha del trabajo por parte de las mujeres de la periferia cuando se casaban: dado que a la mayor parte de estas nuevas esposas les resultaría imposible encomendar a otra persona las tareas domésticas y que la escasa cualificación profesional que por lo general presentaban no les ofrecía ni muchos atractivos ni una mayor retribución que la que deberían destinar a costearse las labores del hogar, optaban por abandonar su puesto de trabajo cuando llegaban al matrimonio.

Una opción que creemos se veía enormemente favorecida en aquellos años por las políticas de empleo, a través de dos tipos de compensación económica a las que no se alude en la citada investigación: la "dote" y los "puntos".

La "dote" era otorgada directamente por las empresas a las mujeres que se casaban y renunciaban a su puesto de trabajo; consistiendo en una cantidad variable en función de su antigüedad en la empresa y que se entregaba a las trabajadoras a la firma del finiquito de la relación laboral. Los "puntos" consistían en una prestación social que las empresas tenían obligación de pagar mensualmente al trabajador por cada familiar directo que éste tuviera a su cargo y que no trabajase ${ }^{9}$. De esta forma,

9 Ya en 1938 la Ley de Bases de 18 de julio establecía subsidios familiares de 30 pesetas mensuales para los trabajadores varones casados y con dos hijos en edad no laboral, ascendiendo la cuantía de la prestación en escala progresiva de 15 pesetas 
aunque su cuantía era variable, pues dependía de la proporción de beneficiarios que hubiera en el conjunto de la plantilla de cada empresa y del número de familiares a su cargo, la garantía de una prestación mínima mensual favorecía el hecho de que la mujer se quedase en el hogar al casarse. De la incidencia de esas políticas socio-laborales dan buena muestra estos dos comentarios de sendas informantes:

Cuando las mujeres se casaban pues les daban la dote, que se llamaba, y se despedian, porque todas querían irse cuando se casaban. Entonces no era como ahora, que las mujeres trabajan de casadas. Entonces después de casadas eran pocas las que se quedaban, a no ser que tuvieran buenos oficios. ¡Vamos!, que fueran unas grandes secretarias o algo así. Pero allí en la fábrica no se quedaba nadie (Entrevista n. ${ }^{\circ}$ 26).

Dejé de trabajar porque me casé. Es que no existía eso de casarse y seguir trabajando. Además, cuando nos casamos pues ya le daban a mi marido casi 500 pesetas por el matrimonio, el plus de no sé qué, lo de los puntos que le llamábamos. Y eso casi equivalía a lo que yo ganaba entonces de sueldo [base], ¿para qué iba yo a seguir trabajando? Si seguía trabajando no le pagaban el plus ese ... yo ya me casé con la cosa esa de no trabajar (Entrevista n. ${ }^{\circ} 16$ ).

En definitiva, la conjunción de ciertas pautas culturales - matrimonio a edad temprana y oposición al trabajo de las esposas- y algunos criterios de racionalidad económica -impulsados, además, tanto por el bajo perfil del empleo conseguido como por las políticas sociolaborales de aquellos años - terminaron por redundar en una baja participación del conjunto de las mujeres villaverdenses en el trabajo asalariado en la economía formal. Sin embargo, esto no quiere decir que las jóvenes solteras no ingresasen - por lo común- en la ocupación pues, como ya se ha observado, desde comienzos de los cincuenta lo hicieron cada vez en mayor medida. Y ello, tanto en las actividades que mayoritariamente parecían destinárseles en 1945 - Servicio Doméstico-, como en los puestos de trabajo industriales que las nuevas fábricas de Villaverde proporcionaban -especialmente Marconi Española, Giralt Laporta, Barreiros Diesel, Manufacturas Metálicas y Standard Eléctrica - o en las cada vez más pujantes empresas madrileñas de la confección en los sesenta - Induyco, Santa Clara, Elca, etc-.

por cada persona más que el trabajador tuviese a su cargo. Posteriormente, la Orden de 26 de marzo de 1946 mandataba la privación de Plus Familiar para aquellos trabajadores cuyas mujeres trabajasen. En suma, la mayor parte de la normativa laboral contenía estipulaciones que "primaban" u "obligaban" - recuérdese el caso de las trabajadoras de RENFE- al abandono del trabajo de las mujeres casadas. Cfr. al respecto G. M. Scanlon 1986, especialmente su capítulo 7: „La 'España Nueva'», pp. 320 y ss. 
Sin duda, con ello contribuyeron a mejorar puntualmente las economías familiares en sus respectivos hogares. Puntualmente, por cuanto su paso por la ocupación asalariada formal fue comparativamente fugaz respecto al de los jóvenes varones, ya que mientras ellos permanecerían ocupados hasta jubilarse, ellas abandonarían el empleo al llegar al matrimonio. Un buen ejemplo de la intervención al unísono de los condicionantes hasta aquí apuntados en la ruptura de la experiencia laboral de las mujeres que llegaban al matrimonio nos lo proporciona el siguiente relato:

Mi mujer trabajó de soltera al menos en tres empresas que yo sepa. Una era de cromados, luego estuvo en Estilográficas Ciros, y cuando ya nos casamos (1958) estaba trabajando en Manufacturas Metálicas. [...] Luego ya, cuando nos casamos, mi mujer no siguió trabajando. Es que estando casada me parece que ya no podía trabajar en Manufacturas, porque les daban una dote y las echaban, pero es que de todas formas yo no quería que siguiera trabajando. [...] porque me gustaba llegar a casa y que estuviera ella. Ella quiso trabajar pero yo no quise, es que entonces eso casi no compensaba. De hecho, yo salía de Renfe y me iba a otro sitio a trabajar, que he estao en dos sitios trabajando mucho tiempo. ¿Hay que llevar dinero?, ¡bueno!, pues yo lo llevaba, pero a mi me gustaba que cuando yo llegara a casa que estuviera ella allí (Entrevista n. ${ }^{\circ}$ 6).

En este caso, y debido tanto al extenuente pluriempleo al que alude el marido, como a que el matrimonio no tuviera que hacer frente al pago mensual del alquiler o que los hijos tardaran en llegar, no hizo falta que la mujer trabajase - asalariadamente - una vez casada, precipitando así su salida de la vida económicamente activa. Sin embargo, aun cuando, a tenor de las entrevistas realizadas, pudiéramos decir que al iniciarse las relaciones conyugales éste era el comportamiento "tipo" en la mayor parte de los casos, en los hogares donde la situación era económicamente más angustiosa -menor nivel salarial, familias más extensas, etc.- o en aquellos donde se pretendía mejorar en alguna medida el escaso bienestar que reportaban los ingresos proporcionados por el trabajo asalariado en la "economía formal", las esposas tuvieron que buscar el modo de contribuir a las economías domésticas, añadiendo a sus labores en la casa otro tipo de actividades.

\section{LA ACTIVIDAD FEMENINA DENTRO Y FUERA DEL HOGAR: TRABAJOS QUE NO RECOGIERON LAS FUENTES SOCIO-DEMOGRÁFICAS}

Al evaluar el papel desempeñado por la mujer dentro de la economía familiar, es importante partir de la consideración de que en todo momento su labor se con- 
sideraba imprescindible para el bienestar de la familia, si bien su contribución a la consecución de este bien no se plasmaba siempre mediante una aportación monetaria directa (Reher y Camps 1991: 83).

Como en los últimos años muchas investigaciones - tanto históricas como del período actual - vienen poniendo de manifiesto en nuestro país, si pudiéramos contabilizar a precios de mercado el trabajo doméstico destinado a la reproducción de la mano de obra que desarrollan las mujeres en los hogares obreros, su cuantía sería en muchos casos incluso superior a los ingresos derivados del trabajo fuera de casa del cabeza de familia ${ }^{10}$.

Tener, criar y cuidar a los hijos; limpiar, fregar y lavar; comprar y cocinar comidas; coser y confeccionar ropa; e incluso realizar las tareas propias de la administración de la casa, eran - y son- labores esenciales para el bienestar familiar ${ }^{11}$. Tareas que, como han subrayado Reher y Camps (1991: 84) a partir de investigaciones propias sobre la población campesina y urbana de la Cuenca del siglo xIX o de los residentes en el cinturón industrial barcelonés a comienzos de éste, ase consideraban más vitales que su [propia] aportación monetaria al seno familiar" cuando las esposas trabajaban asalariadamente. Sin embargo, a pesar de ello -y del importante papel que juegan las labores domésticas de reproducción de la fuerza de trabajo dentro de la dinámica del sistema económico vigente-, que esas tareas nunca se hayan traducido en una aportación monetaria directa ha incidido grandemente en su minusvaloración social, una queja recurrente por parte de nuestras entrevistadas:

Los hombres han tenido que trabajar mucho, pero las mujeres hemos estado también muy esclavas, siempre. Yo, el recuerdo que tengo de mi madre es el de una mujer muy esclava, con siete hijos, pendiente del marido. Porque mi padre venía del trabajo, se lavaba, se arreglaba, que mi madre le tenía que echar hasta el agua en la palangana y prepararle todo en las manos, para que él se fuera a echar su partidita. Y jclaro! pues mi madre muy esclava. [...] Y cuando yo me casé pues por el estilo, porque nosotros no tuvimos familia hasta los 18 meses,

10 A este respecto, y entre otros, puden verse los trabajos de Pilar Pérez-Fuentes 1993 y 1995; Ubaldo Martínez Veiga 1995; los artículos editados en Política y Sociedad, n. ${ }^{\circ}$ 19, mayo-agosto de 1995 (monográfico sobre la economía no monetaria presentado por M.a Angeles Durán); o, por no extendernos, Carmen Sarasúa 1997.

11 Como se suele poner de manifiesto en algunos estudios antropológicos: "[...] madres, hermanas, esposas e hijas son tan necesarias como padres, hermanos, esposos e hijos. Las actividades que ellas realizan no pueden ser sustituidas en condiciones totalmente aceptables. Su ausencia, inevitablemente, endurece las condiciones de vida de los hombres" (García Muñoz 1995: 199). 
pero nos casamos y a los cino días ya tenía yo a mis dos hermanos en casa, jcon eso te digo bastante! Teníamos dos habitaciones, ellos dormían en una y nosotros en otra. [...] yo los tenía como si fueran hijos míos, les lavaba la ropa, les planchaba, la comida, en fin, jtodo!, ¡como a mis hijos! O sea, que yo desde que me casé pues también he tenido que trabajar mucho en mi casa, y cuando vinieron mis hijos pues más. ¡A ver!, que si cuidarlos, que si estar pendiente de ellos. Y luego pues nada: jerseys, calcetinitos, botitas. $Y$ deshacer un jersey y volver a hacer otro, juntando una lana con otra. Y el trabajo de la casa. En fin, lo que hacíamos las mujeres de entonces (Entrevista $n .^{\circ} 16$ ).

Efectivamente, las tareas domésticas ocupaban a "las mujeres de entonces" una gran parte del día, desprovistos como estaban los hogares obreros de electrodomésticos que simplificaran las labores de la casa; de esos "magníficos servidores para la reina del hogar" —como rezaba a menudo la publicidad de la época- que facilitaron después su cometido. Trabajos que, además, se veían dificultados por los graves déficits de equipamiento que presentaron las viviendas y barriadas del sur madrileño durante el período que aquí estudiamos. Y entre ellos, por poner sólo algún ejemplo, los problemas derivados del precario suministro de agua corriente o la escasa dotación comercial existente por entonces en dichas zonas. Circunstancias que imprimían mayor relevancia aún a la doble jornada de trabajo que algunas de estas "amas de casa" se veían obligadas a realizar:

Yo atendía casa, tienda, niña y todo lo que eso conllevaba. Y menos mal que cuando nos vinimos a Villaverde [1956/57] mi madre, que había comprao una [lavadoral Otsein, de esa de rodillos para escurrir la ropa, me la dejó hasta que me pude comprar una. Pero yo tenía que subir el agua del portal, llenar la lavadora, que hacía tres cántaros, llenar la pila, llenar el barreño, todo lo que tenía, cacerolas y todo. Y luego esperar dos días a gastar un poco de las cacerolas para poder poner a calentar parte del agua de la lavadora y lavar con agua templada. Entonces pues lavaba la ropa, que entonces era jabón rallao, no había detergente ni esas cosas, y según se iba lavando la ropa pues la iba dejando en una repisa, y cuando había terminado de lavar pues quitaba el agua y volvía a llenarla de agua limpia para aclarar. $Y$ otra vez vueltas y vueltas hasta que la sacaba ya aclarada y la metía en lejía, en la pila, que es de donde había llenao la lavadora con agua limpia para aclarar, y dejaba en la pila una poca para echarle lejía y meter la ropa que fuese en lejía. Y así. A la mañana siguiente me levantaba a las seis de la mañana y me ponía a planchar, y cuando bajaba a la tienda muchas veces ya llevaba desde las seis de la mañana trajinando, porque ¡claro! que si la niña, que si el desayuno, que si las camas, esto y lo otro. Y los miércoles llegaba el representante tempranito y tenía que atenderlo, porque no podía venir el hombre otro día. En fin, y luego la comida, que como no la hubiera hecho la noche anterior pues me la tenía que dejar hecha también por la mañana, judías, lentejas, garbanzos, lo que fuera iporque mi marido no ayudaba nada! [...] El se tenía que levantar muy temprano, pero yo también. Porque el llegaba a comer y yo tenía que 
tener la comida a la hora, porque tenía 20 minutos para comer y marcharse, que tenía que volver por las tardes para hacer horas extras y traer un poco más de dinero a casa (Entrevista n.$^{\circ}$ 1).

El relato corresponde a una mujer que desde finales de los años cincuenta hubo de conjugar sus esforzadas tareas domésticas con el trabajo derivado de atender la mercería que regentaba, con el fin de complementar el salario ganado por el marido, por entonces oficial administrativo de la RENFE. Y lo hemos traído aquí como ejemplo de una de las múltiples actividades de la mujer dentro del hogar; de los trabajos que tradicionalmente se han venido considerando como parte de sus labores. Con todo, además de esas actividades, también hemos encontrado otras formas de trabajo femenino que, como se dijo en la presentación, permanecieron ocultas, invisibles, para las estadísticas socio-demográficas. Trabajos que estas mujeres debieron acometer, bien por ser las únicas dentro del grupo familiar en edad de trabajar, bien porque los salarios aportados por los otros miembros del hogar eran insuficientes para atender los gastos corrientes de la unidad familiar.

En el primer caso nos estamos refiriendo, casi en exclusiva, a aquellas mujeres que enviudaron a edad temprana y tenían hijos pequeños que alimentar. En esa tesitura, ante la ausencia de otro tipo de solución, sin ningún otro miembro familiar que pudiera emplearse y recibiendo una ínfima pensión por viudedad, estas — por desgracia - "nuevas" cabezas de familia se vieron obligadas a trabajar asalariadamente, teniendo que compatibilizar las faenas fuera de casa con las propias de las labores domésticas ${ }^{12}$. Una circunstancia, ésta de tener que ponerse a trabajar fuera de casa, que muchas veces estigmatizaba a sus protagonistas, pues, de hecho, parecía vivirse en ocasiones como si de un cierto descenso en su posición social se tratase:

Mi madre se quedó viuda en 1950, que mi padre murió de silicosis, como era vidriero pues ... ¡Bueno!, el caso es que yo tenía 10 años y mi hermano 12 . Entonces, al ser viuda de vidriero pues le tenían que permitir entrar a trabajar en Giralt, pero le hicieron la pirula, porque cuando entró no la hicieron fija, la pusieron como destajista. La dijeron: "mira, tú es mejor que para atender a tus niños pues como vas a ganar muy poquito pues que trabajes a tu destajo; aquí tienes unas sacas y se te va a pagar a equis dinero por saca que cosas, y así puedes

12 De la ridícula aportación que las pensiones del tan cacareado "Estado social" franquista procuraban a las economías familiares da buena cuenta el siguiente comentario de una jóven trabajadora por entonces: "Cuando mi padre se murió le quedó a mi madre de pensión 300 pesetas al mes, muy poco. Mi padre murió en el año $64 \mathrm{y}$ le quedó eso de pensión y mi madre tuvo que seguir trabajando de asistenta, y eso que yo entonces ya trabajaba" (Entrevista n. ${ }^{\circ} 28$ ). 
estar y atender a tu casa mientras te sacas un jornal». Que así estuvo mi madre dos años por lo menos, hasta que la incorporaron a la fábrica, porque ya las cosas venían en sacos de plástico y no hacía falta coser. [...] ¡Hombre!, ella dice que lo pasó mal porque como mi padre había sido maquinista y allí todo el mundo nos conocía pues, ¡claro!, que tuvieramos que trabajar las dos allí ... de peones, pues esa situación es la que a ella no le gustaba (Entrevista n. ${ }^{\circ}$ 26).

En el segundo caso -el de las esposas que necesitaban complementar el salario que aportaban los miembros que encabezaban las familiasaparece claramente una situación de insuficiencia de los jornales aportados por los cabezas de familia y, en su caso, otros miembros del hogar ocupados. Y eso que estos trabajadores estuvieron sometidos a condiciones laborales presididas, en general, por la intensificación y extensión de la jornada de trabajo. Destajos y horas extraordinarias extenuantes que, en muchos casos, no llegaban a hacer posible el bienestar del grupo familiar, por lo que sus cónyuges tuvieron que buscar una ocupación sumergida que elevara los ingresos corrientes en sus hogares. Véase un ejemplo de ello a través del siguiente relato:

Nosotros vivíamos medio regular porque nos apañábamos con muy poquito, mi mujer era muy ahorrativa, siempre ha administrao la casa muy bien, como creo que casi todas las mujeres de todos los trabajadores ¿no? Además, luego se puso a trabajar ella, que iba donde la llamaban, a limpiar casas. Que eso pues lo notamos mucho, porque gracias a lo que ella ha trabajao y lo que ella ha ganao pues podíamos comer como quien dice. Porque ya te expliqué que con lo que [yo] ganaba no teníamos casi para vivir. (Entrevista n. $\left.{ }^{\circ} 17\right)^{13}$.

Nuestro informante era por entonces oficial de $2 .^{a}$ en los Talleres de una importante empresa metalúrgica de Villaverde, donde alargaba su jornada laboral realizando tres horas extraordinarias al día; actividad que - repitámoslo otra vez- era insuficiente por entonces para cubrir los gas-

13 Nótese, por otro lado, la importancia que da el marido al papel administrador jugado, también, por la esposa dentro del grupo familiar, y la generalización que hace respecto al conjunto de las mujeres de trabajadores. Una función gestionadora y administradora que, junto a la educación de los hijos, realizaban las esposas por cuanto las extensas jornadas de trabajo a que se veían sometidos sus maridos apenas les dejaba tiempo para ello: "Yo he estado siempre viuda, porque mi marido se iba de madrugada y volvía por la noche, pero de noche ¡eh!, que estaba en casa el ratito de cenar y dormir. [...] [Y] los domingos iba mucho a echar horas, hasta el medio día, muchos domingos. [...] Todo ha corrido por mi cuenta, todo: la casa, los hijos, todo. Aunque esté feo que lo diga, porque es que en realidad no es que él no se preocupara, es que no tenía tiempo, no estaba nunca en casa. Si había que ir al colegio, iba yo; si había que hacer alguna gestión, era yo; si había que solucionar algo siempre era yo; todas las cosas las tenía que hacer yo" (Entrevista n. ${ }^{\circ} 21$ ). 
tos de un grupo doméstico bastante reducido (matrimonio y un hijo pequeño) ${ }^{14}$. Pero ello implicaba el trabajo denodado de su mujer, la doble ocupación femenina a que nos estamos refiriendo y de cuyos extensos menesteres nos da amplia idea el siguiente testimonio de una de aquellas esforzadas protagonistas:

Yo me coloqué en el Banco de España [en 1964], en la limpieza [...]. Pero antes de colocarme alli, como mi marido estuvo mucho tiempo enfermo pues hasta que le quedó la pensión estuve asistiendo en casas particulares de Madrid. Iba por la mañana, íbamos a lavar, íbamos a limpiar, nos daban cinco pesetas ... ¡Fíjate! eso nos daban al día, y dos huevos pa cenar y un trozo de pan, jeso te daban! Que entonces el trabajo no era como el de ahora jeh!, que ahora hay mucha mopa y muchas máquinas. Que entonces era to na más que a base de jabón, estropajo y sosa, y de rodillas. ¡Mucho trabajo! Así que ya ves cómo me podía organizar, pues dejando mi casa arrecogía desde por la mañana. Metí a los dos pequeños, que uno tenía dos añejos todavía, pues en un colegio particular que había aquí, como una guardería, en la Meseta [de Orcasitas], que ya te dije que como mi marido estaba hospitalizao pues me los arrecogía una vecina del patio cuando salían por la tarde, que la mujer, la verdad, pues ha hecho mucho por mí. [...] Es que yo trabajaba to el día, entre la casa y el trabajo [...] yo no he sabío lo que es descansar hasta que me he jubilao casi. En el tiempo del verano me levantaba a las seis de la mañana pa dejar toa mi casa arreglá. Si me tocaba lavar pues me iba a coger el agua, que ya te dije que lo del agua estuvo mucho tiempo mal, porque tenía que ir y venir a la fuente hasta que llenaba los dos barreños, porque lavábamos en el lejío [en un descampao]. Y luego a preparar los chicos para ir al colegio, a prepararles la comida, a hacer la cama, la habitación, aunque como eran sólo dos habitaciones pues había poco que limpiar ¿no? Era pues preparar todo eso y ir a la compra. Luego ya, otro día, pues a lo mejor me tocaba planchar ... y así iba compaginando las cosas. El día que libraba pues me metía de lleno en limpar la casa y todo eso. [...] cuando regresaba por la noche, que llegaba casi a

14 Ni más ni menos, por cierto, que como otros muchos matrimonios convecinos cuyos cabezas de familia trabajaban, por ejemplo, en la Construcción, una actividad laboral que solía estar peor remunerada. Como nos cuenta la esposa de quien fuera uno de esos "peones de albañil", la manutención de los hijos -en su caso cinco-y el pago del alquiler de una vivienda fueron dos importantes motivos para que ella decidiera ponerse a trabajar en una empresa de limpieza, justo hasta que sus hijos fueron entrando en la ocupación: “Nosotros vivíamos en casa de mis padres, pero ya éramos muchos, éramos 15 allí, porque mis hermanos todavía no se habían casao. Y en el año 66 nos fuimos de alquiler, que teníamos que pagar dos mil y pico pesetas, que hoy eso no es ná, pero entonces era ... con decirte que me tuve que poner a trabajar en la empresa de limpieza. Estuve poco tiempo [tres años y medio], pero me tuve que poner a trabajar porque no podíamos pagar el alquiler. Con lo que ganaba mi marido, que se hartaba a hacer horas, no teníamos na más que pa comer, que ya te he dicho que teníamos cinco chicos pequeños. Ya te digo que estuve poco porque en cuanto mis hijos se fueron poniendo a trabajar pues yo ya lo dejé y me quedé en mi casa tranquilamente" (Entrevista $n^{\circ} 21$ ). 
las diez, pues la misma faena, arreglar a los chicos, lavarlos, darles de cenar, acostarlos, y tó ese jaleo me traía, un día sí y otro también (Entrevista n. ${ }^{\circ} 30$ ).

O sea, literalmente, trabajar durante todo el día para sacar adelante a su familia. Extensas jornadas de trabajo que también tuvieron que realizar otras muchas mujeres, aunque para ello no les hizo falta salir de sus hogares ya que el trabajo entraba en ellos. Si el empleo como asistentas o limpiadoras fue la actividad prototípica de aquellas esposas que trabajaron fuera de sus casas, la confección lo fue para el caso de las que lo hicieron a domicilio; una tarea a la que, muy a menudo, se aplicaron también las jóvenes mujeres del hogar. Un trabajador de la industria de la automoción que a finales de los cincuenta vivía en el domicilio de sus tíos recuerda cómo, a pesar de que tanto él como el cabeza de familia -operario de una industria cerámica- aportaban sus respectivos salarios a la economía doméstica, el componente femenino del grupo familiar también debía contribuir a ella para mejorar así su bienestar material:

Mi tía hacía pantalones, con una máquina en su casa. Alli trabajaba todo dios, entonces era demasiao, trabajábamos todos y no había dinero. Eso es lo que pasaba entonces, que trabajábamos todos y ibas mal, porque se ganaba tan poco que es que había que arrimar el hombro todos. Y mi tía pues en los ratos libres que tenía pues hacía pantalones. Pero no creas tú que lo de la casa no tenía tarea ¡eh!, que éramos cinco y yo seis. Bueno, pues además de eso liá siempre con la máquina de coser haciendo pantalones, que era de esas de pié hasta que ya se compró al mucho una elécrica, de las primeras que salieron. $Y$ las chicas pequeñas pues ayudaban en lo que podían, sacar hilvanes y cosas de esas. Y mi prima la mayor decidió salirse de donde estaba y compraron otra máquina y se puso también a hacer pantalones, que ganaba más que donde trabajaba. Pero trabajaban mucho jeh!, porque mi tía y la mayor no paraban en la máquina, y las dos pequeñas pues con los pespuntes, los hilvanes, todo eso (Entrevista n. $\left.{ }^{0} 8\right)^{15}$.

Evidentemente, que las tareas como asistentas domésticas y costureras fueran los más comunes entre las esposas que trabajaban - fuera o den-

15 Y otro ejemplo similar nos lo ofrecía una mujer que se casó en los años sesenta, motivo por el que dejó su anterior trabajo. Sin embargo, como explica ella misma, cuando acabó de criar a sus hijas decidió trabajar a domicilio como trabajadora "sumergida" de la confección: "Bueno, luego ya en mi casa pues hacía algunas cosas de costura, cosía pantalones y esas cosas, porque yo siempre me buscaba algo para ganarme un dinero. Pero sólo cuando ya crié a mis hijas, mientras tanto no, porque mis hijas se llevaban muy poco -18 meses- y jclaro! tenía que estar muy pendiente de ellas y de mi marido, que trabajaba de tarde y yo tenía que tener las cosas [de la casal hechas por la mañana, para que mi marido se fuera ya comido a trabajar, que venía de un taller donde estaba haciendo horas por la mañana, comía, y se iba a la fábrica por la tarde. (Entrevista $n .^{\circ} 28$ ). 
tro del hogar, respectivamente- no quiere decir que no existieran otras donde éstas pudieron emplearse. Respecto al trabajo fuera de la casa, el siguiente testimonio, proporcionado por un hombre que tenía una churrería en Orcasitas desde finales de los cincuenta, nos proporciona un ejemplo de otros trabajos "alternativos", y no sólo para las esposas sino también para otros miembros familiares en edad no laboral:

Yo tenía por aquellos entonces 12 y 14 muchachos vendiendo churros, chicos y chicas, que les daba un tanto por cada cesta que vendían [...] muchachos pequeños, que todavía iban al colegio pero se querian ganar una perras, y mujeres ya casás, porque entonces todo lo que uno pudiera llevar a su casa era poco (Entrevista n. ${ }^{\circ}$ 18).

En cuanto a otras posibles formas de trabajo a domicilio durante el período que aquí estudiamos, véase el siguiente comentario de una trabajadora de la industria del vidrio. En él se refiere a las "taselas", unos cuadraditos vidrio-cerámicos muy usados, por ejemplo, como material de revestimiento en los frisos de los accesos y estaciones del Metropolitano madrileño. Con el fin de facilitar su colocación final en las obras donde se utilizaban debían ser presentados antes de su posterior venta a las empresas constructoras en unos paneles de papel de estraza engomado. Un trabajo que la empresa fabricante externalizaba, llevándolo al interior de los hogares obreros:

Allí las chicas se llevaban trabajo a destajo a sus casas. [...] se lo pagaban por paneles de taselas hechos. Algunas se iban a la otra nave cuando salían de trabajar y se quedaban allí haciendo taselas, pero la mayoría se las llevaban a sus casas o a sus familiares para que los hicieran. [...] Mucha gente. Seguro que si preguntas aquí en Villaverde sale bastante gente que te dice que ha hecho taselas para la fábrica, destajistas. Iban a la fábrica a por ello, como si yo me voy ahora a un taller de confección y me traigo ropa para coser (Entrevista n. ${ }^{\circ} 26$ ).

Realmente, resulta significativo que nuestra entrevistada termine el párrafo equiparando las dos formas de trabajo a domicilio a las que aquí hemos hecho referencia. Y ello por cuanto la manufactura de confección a domicilio, según se trasluce de su afirmación, forma parte del conjunto de "estrategias" que hoy en día - como ayer y antes de ayer- ponen en marcha las familias obreras más modestas para elevar los ingresos en sus hogares: la puesta en el trabajo de todos los recursos humanos disponibles ${ }^{16}$. Un patrón básico de actuación implícito en la "cultura obrera",

16 Como, de igual forma, un viaje hacia el centro de Madrid por las mañanas $\longrightarrow$ de vuelta al medio día-, en cualquiera de los transportes públicos de que hoy 
entendida ésta en términos amplios: "La cultura de clase obrera no es una respuesta histórica a las condiciones existenciales, es, más bien, un conjunto intensamente conservador y tradicional de prácticas familiares a la hora de afrontar las difíciles circunstancias materiales" (Pahl 1991: 199).

En definitiva, y como creemos haber mostrado aquí, el hecho de que los jornales ganados por los cabeza de familia no bastasen para mantener adecuadamente sus hogares, por poco extensos que éstos fueran, y que la entrada en la ocupación de los hijos - generalmente puestos a trabajar en cuanto tenían edad para ello- tampoco paliase grandemente aquella situación de precariedad, hizo que sus mujeres y madres tuviesen que acometer en muchos casos una doble jornada de trabajo: dentro y fuera del hogar; de forma especial durante la fase más crítica del ciclo vital familiar. Así, estas esforzadas mujeres pudieron contribuir, junto a sus esposos e hijos, a mejorar las economías domésticas, aportando también sus ingresos para hacer frente al pago de alquileres comparativamente caros respecto a los salarios existentes, a sufragar los gastos corrientes de manutención y vestido del grupo familiar, o a pagar los plazos necesarios para adquirir una vivienda en propiedad y algunos muebles con que equiparlas.

\section{BIBLIOGRAFÍA CITADA}

AlONSO HiNOJAL, I. 1969. Algunos aspectos sociológicos de un barrio de incorporación. Madrid: Ministerio de la Vivienda, Secretaría General Técnica.

ANDERSON, M. 1988. Aproximaciones a la bistoria de la familia occidental (1500-1914). Madrid: Siglo XXI Ed.

Ayuntamiento De Villaverde. 1945. Padrón Municipal de Habitantes de 1945. Madrid: Archivo de Villa de Madrid, Secretaría, Sección 'Pueblos Anexionados'.

BABIANO, J. 1995. Emigrantes, cronómetros y buelgas. Un estudio sobre el trabajo y los trabajadores durante el franquismo (Madrid, 1951-1977). Madrid: Siglo XXI-Fundación $10^{\circ}$ de Mayo.

BAHAMONDE MAGRO, A. 1993. La sociedad española de los años 40. Madrid: Historia 16 [Colección "Cuadernos del mundo actual"].

BARCIELA LÓPEZ, C. 1998. «Franquismo y corrupción económica». Historia Social 30: 83-96. BURGUière, A., et al. 1988. Historia de la familia. Madrid: Alianza.

CÁmARA OfICIAL DE COMERCIO Y DE LA INDUSTRIA DE MADRID. 1951. La economía de Madrid en 1950 (Memoria Comercial e Industrial). Madrid: Gráfica Administrativa

disponen en Villaverde, nos llevaría a preguntarnos ¿dónde van muchas de las mujeres que viajan junto a nosotros? La respuesta la obtendriamos con sólo prestar algo de atención a sus conversaciones ... sobre las condiciones de trabajo que les depara su "empleo sumergido" como asistentas de hogar. 
CARRERAS, A. 1989. "Depresión económica y cambio estructural durante el decenio bélico (1936-1945)», en J. L. García Delgado (ed.), El primer franquismo. España durante la segunda guerra mundial: 3-33. Madrid: Siglo XXI.

CHAYANOv, A.V. 1985. La organización de la unidad económica campesina. Buenos Aires: Ed. Nueva Visión.

ChOmbarT DE LAUWE, P. 1978. "La vida familiar y los presupuestos", en G. Friedman y P. Naville (dirs.), Tratado de Sociología del Trabajo: 329-340. México: Fondo de Cultura Económica.

EsPINA, A. 1982. "La participación femenina en la actividad económica. El caso español", en R. Conde (comp.), Familia y cambio social en España: 283-349. Madrid: Centro de Investigaciones Sociológicas.

FERNÁNDEZ DE CASTRO, I. 1973. La fuerza de trabajo en España. Madrid: Edicusa.

FERNÁNDEZ GÓMEZ, J. A. 2000. La industrialización de Villaverde. Emigración, Condiciones de Trabajo y Vida en el sur de Madrid (1940-1965). Tesis Doctoral. Sociología III. Facultad de Ciencias Políticas y Sociología de la U.C.M.

FERNER, A. y Ll. FINA. 1988. "La dinámica salarial durante el franquismo. El caso de Renfen. Revista de Historia Económica 1 (Año VI): 131-161.

FOESSA-Cáritas Diocesana de Madrid. 1967. Informe sociológico sobre la situación social en Madrid. Madrid: Euramérica.

GARCía MUÑOZ, A. 1995. Los que no pueden vivir de lo suyo. Trabajo y cultura en el Campo de Calatrava. Madrid: Ministerio de Agricultura, Pesca y Alimentación.

HARRIS, C. C. 1986. Familia y sociedad industrial. Barcelona: Península.

InstituTO NACIONAL DE EsTAdística. 1950. Censo de la Población de España [Tomo II. Municipio de Villaverde]. Madrid: Instituto Nacional de Estadística.

Martínez Veiga, U. 1995. Mujer, trabajo y domicilio. Los origenes de la discriminación. Barcelona: Icaria.

MINISTERIO DE LA VIVIENDA. 1961. Plan General de Ordenación Urbana del Área Metropolitana de Madrid. Madrid: Comisaría General para la Ordenación Urbana de Madrid y sus alrededores [Volúmen V-a (Memoria)].

PAHL, R.E. 1991. Divisiones del trabajo. Madrid: Ministerio de Trabajo y Seguridad Social.

PÉREZ FUENTES, P. 1993. Vivir y morir en las minas. Estrategias familiares y relaciones de género en la primera industrialización vizcaina, 1873-1913. Bilbao: Ed. Universidad del País Vasco.

- 1995. "El trabajo de las mujeres en la España de los siglos XIX y Xx. Consideraciones metodológicas". Arenal 2: 219-245.

REHER, D. S. y E. CAMPS. 1991. "Las economías familiares dentro de un contexto histórico comparado". Revista Española de Investigaciones Sociológicas 55: 65-91.

SARASÚA, C. 1997. "Los campesinos y sus familias en la España del siglo XVIII. Un estado de la cuestión. III Seminario sobre economía y estrategias familiares. Barcelona: Universitat Pompeu Fabra. [Mimeo].

SCANLON, G. M. 1986. La polémica feminista en la España contemporánea (1868-1974). Madrid: Akal.

VelARDE FUeRTES, J. 1969. Sobre la decadencia económica de España. Madrid: Tecnos. 


\section{ANEXO ESTADÍSTICO}

TABLA 1

POBLACIÓN RESIDENTE EN VILLAVERDE SEgúN GRADO DE PARENTESCO, ACTIVIDAD Y OCUPACIÓN EN 1945.

\begin{tabular}{|c|c|c|c|c|c|c|}
\hline \multirow{3}{*}{$\begin{array}{l}\text { GRADO DE PARENTESCO } \\
\text { Cabeza Familia ......... } \\
\text { Esposas ......................... }\end{array}$} & \multirow{3}{*}{\begin{tabular}{|c|} 
POBLACIÓN \\
TOTAL \\
3.311 \\
2.747
\end{tabular}} & \multicolumn{2}{|c|}{$\begin{array}{c}\text { POBLACIÓN ACTTVA } \\
(63,6 \%)\end{array}$} & \multicolumn{2}{|c|}{$\begin{array}{c}\text { POBLACIÓN OCUPADA } \\
(30,2 \%)\end{array}$} & \multirow{2}{*}{\begin{tabular}{|r|}
$\%$ ACTVOS \\
OCUPADOS \\
93,5
\end{tabular}} \\
\hline & & 3.151 & 32,6 & 2.946 & 64,5 & \\
\hline & & 2.678 & $2 /$ & 27 & 0,5 & 1,0 \\
\hline & 7.685 & 2.967 & 30,7 & 1.197 & 26,0 & 40 \\
\hline 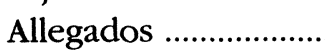 & 1.281 & 721 & 7, & 309 & 6,5 & 42,9 \\
\hline Otros & 182 & 155 & 6 & 118 & 2,5 & 76,1 \\
\hline IOIAL. & 15.207 & 9.672 & 100 & 4.597 &, 0 & 47,5 \\
\hline
\end{tabular}

Fuente: Ayuntamiento de Villaverde (1945). Elaboración propia.

TABLA 2

PORCENTAJE DE FRECUENCIAS OBSERVADAS EN LOS SALARIOS PERCIBIDOS POR LOS HIJOS DE LAS FAMILIAS VILLAVERDENSES EN 1945. VARONES Y MUJERES.

\begin{tabular}{|c|c|c|}
\hline SALARIOS PERCIBDOS & \% DE HJOS QUE LOS PERCIBIAN & \% DE HIAS QUE LOS PERCIBIAN \\
\hline Menos de 3 pesetas ............ & 1,3 & 26,2 \\
Entre 3 y 5 pesetas .......... & 15,1 & 29,1 \\
Entre 5,5 y 7,5 pesetas ....... & 13,8 & 22,3 \\
Entre 7,6 y 9,5 pesetas ....... & 10,8 & 7,8 \\
9,85 pesetas y más ............ & 59,0 & 14,6 \\
\hline
\end{tabular}

Fuente: Ayuntamiento de Villaverde (1945). Elaboración propia. 